\title{
PREVALÊNCIA DAS PRINCIPAIS MANIFESTAÇÕES BUCAIS EM CRIANÇAS E ADOLESCENTES COM ANEMIA FALCIFORME
}

Danielle Del SANTO, Giovana GABARDO, Milena ALBINI, Norma Suely Falcão de Oliveira MELO, Antônio Adilson Soares de LIMA

O presente trabalho tem o objetivo de avaliar as manifestações bucais da doença falciforme em crianças e adolescentes atendidas no centro de hematologia do HC/UFPR. No período de maio a setembro de 2009, foram avaliados 29 pacientes, entre crianças e adolescentes até 18 anos. A partir da realização de um exame clinico sob luz artificial, avaliou-se a freqüência com que ocorriam as seguintes alterações: hipoplasia de esmalte, palidez de mucosa, atraso ou adiantamento da erupção dentária nas dentições decídua ou permanente e história de dor de dente associada a dentes sem lesão de cárie. A palidez de mucosa acometeu $10 \%$ dos pacientes avaliados. Em 14\% da amostra pesquisada houve alteração na erupção dos dentes. A hipoplasia de esmalte teve uma prevalência de $45 \%$, sendo $10 \%$ de hipoplasia generalizada e $35 \%$ de hipoplasia localizada em unidade dentária. $\mathrm{O}$ aspecto clínico das alterações dentárias foi de manchas brancas, manchas escuras e cavitação no esmalte dentário. Nenhuma paciente relatou queixa de dor de dente relacionada a dentes sem lesão cariosa. Conclusão: A doença falciforme esta relacionada com alterações nos tecidos bucais, como palidez de mucosa e hipoplasia de esmalte dental.

Palavras-chave: Anemia hemolítica; Manifestações bucais; Anemia falciforme 